"What am I to make of this threatening disruption in my routine, what are you [the doctor] proposing to do about it, and what overall effect might the situation, and your proposed solutions have on my life?" As Erving Goffman has said, doctors have the special job of informing their patients "who they are going to have to be." Although the answers to these existential questions may depend on facts, they are fundamentally buried in context and judgment.

How does this relate to e-learning? Simple. The strength of e-learning is also its weakness. What we have come to recognise as the information revolution is just another, albeit amazingly effective, way to deliver information, but it only makes the challenge of selection more stark. We confuse information with knowledge and knowledge with judgment. While correlations certainly exist among these dimensions, the pathways from one to the other are unclear and variable. Just getting the theoretical knowledge about $\beta$ blockers into the hands of doctors is patently not enough. Getting them to do the right thing at the right time is the trick. So the real challenge to e-learning enthusiasts is to enhance the judgment of practitioners, to find ways to ensure that that "expert judgment" can be transferred to doctors in the field.

Few examples exist of how this can be done. The problem is that, in our zeal to encourage right action, we usually send out facts and rules rather than useful guides to judgment. If we are to learn any lesson from our early enthusiasm for practice guidelines, it should be that medical practice is too complex to be dependent on rules that presume that context and content can be encapsulated in simple operating procedures. "Each patient is a universe of one," as Eric Erikson reminded us $^{6}{ }^{6}$ and I suppose the rest is commentary.

The clue that we need to follow depends not only on new technology, but also on our oldest tool, which is human interaction. Call it what you will; detailing, apprenticeship, peer mentorship, or discussion groups are all different responses to the necessity for judgment to be "come upon" in practice. "I get by with a little help from my friends," as the Beatles said.

Medical education has enshrined apprenticeship as one of its critical tools. Thus the almost universal requirement for observed traineeships with graded responsibility as part of education and licensure, and the rhetoric we use when assuring the public of the role of peer review in the maintenance of high standards of practice. The ubiquity of these requirements is at least partly explained by our tacit recognition that, unlike information and knowledge, the transfer of judgment demands a working collaboration. I am reminded of hours spent with students, residents, and fellows in conversations that might well have sprung from Schon's book on the reflective practitioner. ${ }^{4}$

Student (leaving the examining room with the attending doctor): "Why did you ask that in that particular way?"

Teacher: "Well I'm not sure but it seemed at the moment in this particular situation that Ms B needed to hear those words before she could agree to surgery."

When technology can help forge that kind of relationship, I'm ready to buy.

Daniel J Klass director of the quality management division College of Physicians and Surgeons of Ontario, 80 College Street, Toronto, Ontario, Canada M5G 2E2

(dklass@cpso.on.ca)

Competing interests: DJK and the organisation that employs him share a vested interest in improving collegial relationships among the doctors of Ontario.

1 Ludmerer K. Learning to heal. New York: Basic Books, 1985:66.

2 Muller S. Physicians for the twenty-first century: report of the project panel on the general professional education of the physician and college preparation for medicine. J Med Educ 1984;59:part 2.

3 Coggeshall L. Planning for medical progress through education. Evanston, Il, Association of American Medical Colleges, 1966.

Schon D. The reflective practitioner. New York: Basic Books, 1983.

Goffman E. Stigma: notes on the management of spoiled identity. New York: Simon and Schuster, 1963.

6 Erikson E. The nature of clinical evidence. In: Lerner D, ed. Evidence and inference. Glencoe, Il: Free Press of Glencoe, 1958.

\title{
The first generation of e-patients
}

\section{These new medical colleagues could provide sustainable healthcare solutions}

F or many citizens of most developed countries, the internet has become a powerful and familiar healthcare tool..$^{1-3}$ About half of adults in the United States have looked for health information on the net, making this the third most popular online activity. $^{2}$ E-patients (we include both those who seek online guidance for their own ailments and the friends and family members who go online on their behalf) report two effects of their online health research"better health information and services, and different (but not always better) relationships with their doctors." Based on our own observations, the expert opinions of colleagues, a variety of e-patient and provider surveys, and a few more rigorous trials, we offer five tentative conclusions regarding the emerging world of the e-patient.
Firstly, many clinicians have underestimated the benefits and overestimated the risks of online health resources for patients. We agree with Eysenbach that many medical researchers have become so "distracted by focusing on the negative aspects of the internet" that they have overlooked the benefits it provides. ${ }^{1}$ Reports of patients coming to harm as the result of online advice are rare, whereas accounts of those who have obtained better care, averted medical mistakes, or saved their own lives are common. ${ }^{45}$ Many e-patients say that the medical information and guidance they can find online is more complete and useful than what they receive from their clinicians. ${ }^{56}$

A reading list and web resources are on bmj.com

\section{Papers $p 1166$ \\ Pesp 1166}


Secondly, medical online support groups have become an important healthcare resource. These groups now provide emotional support, guidance, health information, and medical referrals for nearly all medical conditions-around the world, 24 hours a day and seven days a week, for free. They support self education and self responsibility, encourage patients' initiative and assertiveness, and provide members with an opportunity to help others. ${ }^{56}$ Some e-patient groups, for example, the Life Raft Group (www.liferaftgroup.org), a support group for gastrointestinal stromal tumours, conduct patient initiated clinical research. The group's science team includes a virologist, a microbiologist, a doctor or surgeon, a physicist, an oncologist, and a human genome researcher-all patients or family care givers.

Other groups have established tissue banks or developed patient registries. ${ }^{7}$ For the sickest patients and for those with rare diseases, online support groups can sometimes be more important resources than physicians for many aspects of medical care. ${ }^{6}$ For patients without access to competent professional care, these groups can be the only source of reliable medical guidance. As Eysenbach et al note elsewhere in this issue, it may not be possible to appraise the value of these patient initiated, patient developed resources via the techniques typically used to evaluate professional interventions $^{8}$ (p 1166).We need to develop new tools and methods that can help patients and professionals work together to better understand their dynamics and their potentials.

Thirdly, the net friendliness of clinicians and provider organisations-as rated by the e-patients they serve-is becoming an important new aspect of healthcare quality. Net friendly clinicians support their e-patients' new abilities, encourage them to share the results of their online research, and communicate with them by email. ${ }^{9}$ When clinicians respond negatively to e-patients' requests to discuss materials they have found online and act as if they feel that their authority is being challenged by such requests, it may damage or disrupt the doctor patient relationship. ${ }^{10}$

Fourthly, ehealth researchers should realise that we are witnessing the most important technocultural medical revolution of the past century. We must move beyond critiquing the content of websites, developing proprietary systems, and evaluating the effectiveness of professional interventions. A number of insightful studies of the emerging culture of e-patients have been published, mostly in the social science literature. But they are rarely cited in mainstream medical journals, and their conclusions are unknown to most clinicians.

Much of the fundamental research in this emerging field remains to be done-for example, a census of online support groups, studies of the patient centred email networks that arise when a loved one is ill, and evaluations of the benefits that online patient helpers can provide. ${ }^{11}$ We need more pilot studies: pilots in which patients are taught to provide their own medical care with the best support information technology can provide, ${ }^{12}$ pilots in which professionals and patients explore new ways to work together to care for other patients, and pilots in which teams of professionals and patients look for, evaluate, develop, or apply other new models of e-patient innovation.

Fifthly, we suspect that the emerging world of the e-patient cannot be fully understood and appreciated in the context of pre-internet medical constructs. The medical world view of the 20th century did not recognise the legitimacy of lay medical competence and autonomy. Its metrics, research methods, and cultural vocabulary are poorly suited to studying this emerging field. Something akin to a major system upgrade in our thinking is needed, a new cultural operating system for health care in which e-patients can be recognised as a valuable new type of renewable resource-managing much of their own care, providing care for others, helping professionals improve the quality of their services, and participating in collaborations between patients and professionals. Given the recognition and support they deserve these new medical colleagues may help us find sustainable solutions to the seemingly intractable problems that now plague all modern systems. ${ }^{13}$

\section{Tom Ferguson senior research fellow}

Pew Internet and American Life Project, 3805 Stevenson Avenue, Austin, TX 78703, USA (doctom@doctom.com)

\section{Gilles Frydman president}

Association of Online Cancer Resources, 173 Duane Street, New York, NY 10013, USA (gfrydman@acor.org)

Funding: Part funded by Robert Wood Johnson Foundation grant \#43806

Competing interests: None declared.

1 Eysenbach G. The impact of the internet on cancer outcomes. CA Cancer J Clin 2003;53:356-71. http://caonline.amcancersoc.org/cgi/content/ full/53/6/356 (accessed 28Apr 2004).

2 Fox S, Fallows D. Internet health resources: health searches and email have become more commonplace, but there is room for improvement in searches and overall internet access.: Washington DC, Pew Internet \& American Life Project, July 16, 2003. www.pewinternet.org/reports/pdfs PIP_Health_Report_July_2003.pdf (accessed 29 Apr 2004).

3 Spadaro R. European Union citizens and sources of information about health. Eurobarometer 58.0. The European Opinion Research Group, European Union, Brussels, Belgium, March 2003. http://europa.eu.int/ comm/health/ph_information/indicators/pub_indic_data_en.htm (accessed 12 Mar 2004)

4 Fox S, Lee R. Vital decisions: how internet users decide what information to trust when they or their loved ones are sick. Washington DC, Pew Internet \& American Life Project, 22 May, 2002. www.pewinternet.org/ reports/toc.asp?Report $=59$ (accessed 3 May 2004).

5 Ferguson T. God bless my CML support group: an interview with Gabe Lewis, MD. The Ferguson Report 2002;8. www.fergusonreport.com/ articles/fr00803.htm (accessed 3 Mar 2004.)

6 Ferguson T, Kelly B. E-patients prefer egroups to doctors for 10 of 12 aspects of health care. The Ferguson Report 1999;1. www.fergusonreport.com/articles/fr039905.htm (accessed 6 May 2004.)

7 Solovitch S. The citizen scientists. Wired 2001;9(9). www.wired.comwired archive/9.09/disease.html (accessed 23 Mar 2004.)

8 Eysenbach G, Powell J, Englesakis M, Rizo C, Stern A. Health related virtual communities and electronic support groups: systematic review of the effects of online peer interactions. BMJ 2004:328:1166-70.

9 Ferguson T. How I became a net-friendly clinician: an interview with Daniel Z Sands. The Ferguson Report 2004;10 (in press).

10 Murray E, Lo B, Pollack L, Donelan K, Catania J, Lee K, Zapert K, Turner $\mathrm{R}$. The impact of health information on the internet on health care and the physician-patient relationship: national US survey among 1050 US physicians. J Med Internet Res 2003;5(3):e17, www.jmir.org/2003/3/e17/ (accessed 20 Mar 2004)

11 Ferguson T. Online patient-helpers and physicians working together: a new partnership for high quality health care. BMJ 2000;321 1129-32.

12 Bodenheimer T, Lorig K, Holman H, Grumbach K. Patient self management of chronic disease in medical care. JAMA 2002;288:2469-75.

13 Ferguson T. Online health and the search for sustainable healthcare. The Ferguson report 2002;9. www.fergusonreport.com/articles/fro0901.htm (accessed 6 Mar 2004.) 